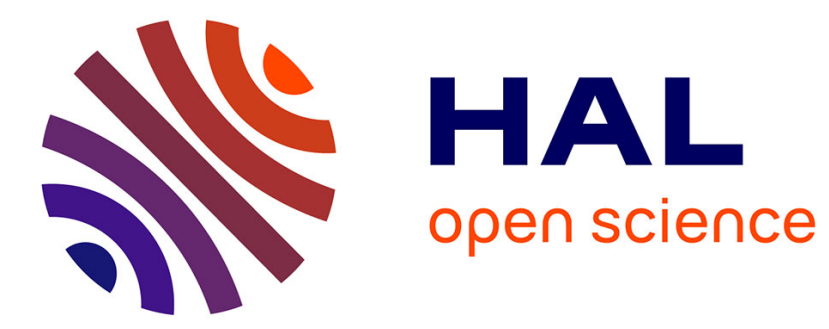

\title{
Characterization of Core-Shell Alginate Capsules
}

Mariana Pereda, Denis Poncelet, Denis Renard

\section{To cite this version:}

Mariana Pereda, Denis Poncelet, Denis Renard. Characterization of Core-Shell Alginate Capsules. Food Biophysics, 2019. hal-02530956

\section{HAL Id: hal-02530956 https://hal.inrae.fr/hal-02530956}

Submitted on 3 Apr 2020

HAL is a multi-disciplinary open access archive for the deposit and dissemination of scientific research documents, whether they are published or not. The documents may come from teaching and research institutions in France or abroad, or from public or private research centers
L'archive ouverte pluridisciplinaire HAL, est destinée au dépôt et à la diffusion de documents scientifiques de niveau recherche, publiés ou non, émanant des établissements d'enseignement et de recherche français ou étrangers, des laboratoires publics ou privés. 


\title{
Characterization of Core-Shell Alginate Capsules
}

\author{
Mariana Pereda ${ }^{1,2,3} \cdot$ Denis Poncelet $^{2} \cdot$ Denis Renard $^{3}$
}

Received: 1 March 2019 / Accepted: 27 June 2019

(C) Springer Science+Business Media, LLC, part of Springer Nature 2019

\begin{abstract}
A new droplets millifluidic/inverse gelation based process was used to produce core-shell alginate milli-capsules. Water-in-oil (W/O) emulsion dispersed phase containing $\mathrm{Ca}^{2+}$ ions was directly injected into a continuous alginate phase to generate a secondary $\mathrm{W} / \mathrm{O} / \mathrm{W}$ emulsion. Due to the cross-linking of alginate molecules by $\mathrm{Ca}^{2+}$ ions release, core-shell milli-capsules were formed with a very high oil loading. The influence of the curing time and of the storage conditions on capsules physico-chemical properties were investigated. It was first found as expected that alginate membrane thickness increased with curing time in the collecting bath. However, a plateau was reached for the higher curing times, in close relation with previous observations (Martins, Poncelet, Marquis, Davy, \& Renard, 2017b) that an external oil layer surrounded the surface of W/O emulsion drops that acted as a barrier and hindered the release of aqueous $\mathrm{CaCl}_{2}$ droplets during curing time. Compression experiments on individual capsules revealed that alginate membrane thickness was inversely related to its mechanical properties, i.e. the thicker membrane, the lower surface Young modulus. Surface Young modulus ranged from 61 to $26 \mathrm{~N} / \mathrm{m}$ at curing times of 3 and $45 \mathrm{~min}$, respectively. This result was explained in terms of enhanced swelling properties of alginate membrane with curing time or storage conditions. Drying capsules led to much more resistant membranes due to the loss of water. Oil loading of $80 \mathrm{wt} \%$ was obtained for dry capsules whatever the conditions used.
\end{abstract}

Keywords Millifluidic $\cdot$ Encapsulation $\cdot$ Inverse gelation $\cdot$ Alginate $\cdot$ Sunflower oil

\section{Introduction}

The study of microcapsules based on biodegradable polymers is of great importance in current scientific research worldwide due to the unusual combination of properties and versatility of these materials.

Electronic supplementary material The online version of this article (https://doi.org/10.1007/s11483-019-09595-x) contains supplementary material, which is available to authorized users.

Denis Renard

denis.renard@inra.fr

1 Institute of Material Science and Technology (INTEMA) - National University of Mar del Plata, Juan B. Justo 4302, 7600 Mar del Plata, Argentina

2 Process Engineering for Environment and Food Laboratory, ONIRIS, F-44322 Nantes, France

3 UR1268 Biopolymères Interactions Assemblages, INRA, 44316 Nantes, France
Microencapsulation avoids the degradation and volatilization of bioactives, protecting and preserving their biological activity and active functional ingredients. The microencapsulation technique has been mainly described as a process in which small particles or droplets are surrounded by a homogeneous or heterogeneous coating, forming beads or capsules with various applications [1]. There are three major fields of application: food production, e.g. enhancement of nutrition by encapsulated vitamins, minerals or even pro-biotic bacteria; cosmetic industry, where encapsulation of colors and flavors became more and more popular within the last years; and drug delivery field.

Oils are widely applied in the formulation of foods, pharmaceutical and cosmetic products; however, they are often volatile, labile and sensitive to environmental factors such as heat, light, water and oxygen [2]. An efficient strategy to decrease their sensitivity towards environmental conditions consists of its encapsulation in inert polymer matrix using gelation/emulsification technique [3-5].

Alginate is one of the most widely used biocompatible polymers in microencapsulation, as it forms a highly versatile, biocompatible and nontoxic matrix of gel that protects the 
active components of factors such as heat and moisture thereby enhancing stability and bioavailability. Alginates are algal polysaccharides consisting of a linear chain of (1-4) linked residues of $\beta$-D-mannuronic acid $(\mathrm{M})$ and $\alpha$-L-guluronic acid $(G)$ in different proportions and sequential arrangements [6]. This polymer has a remarkable property of quick gelation in presence of divalent ions such as calcium ions $\left(\mathrm{Ca}^{2+}\right)$.

Among the different methods used to prepare beads of gelled alginate, the most widely used encapsulation method is the simple extrusion/external gelation [7, 8], wherein the formation of beads containing the solution of alginate and the active to be encapsulated is accomplished by using an extruder device dripping to a bath of $\mathrm{CaCl}_{2}$ solution which induces alginate gelation [1]. The main limitations of this technique are the large size of beads formed, which depends on the diameter of the nozzle extruder, the large quantity of oil used to generate emulsion drops which is generally wasted, and the difficulty of large scale production because beads are formed one by one. One alternative to reduce size is therefore to spray alginate solution rather than dripping to a bath of $\mathrm{CaCl}_{2}$ solution [7].

On the other hand, in the inverse gelation mechanism, oil and $\mathrm{CaCl}_{2}$ solution are emulsified and added dropwise into an alginate solution bath [9], where $\mathrm{Ca}^{2+}$ ions diffuse from the emulsion drop to the alginate bath cross-linking the surrounding alginate molecules [9]. This technique allows producing coreshell capsules with an oil loading of nearly $100 \%(v / v)$ for dry capsules by using the dispersion-inversion gelation technique [10]. In addition, the production of microcapsules using droplets millifluidic is a promising strategy for oil encapsulation and allows the easy production of highly controlled and uniform microcapsules from $\mathrm{W} / \mathrm{O}$ emulsions [11]. A similar droplets millifluidic set-up was used to produce core-shell alginate capsules with an aqueous core instead of an oil core [12]. The millifluidic device used in [11] consisted in a co-axial flow focusing geometry; water-in-oil (W/O) emulsion drops containing $\mathrm{Ca}^{2+}$ are directly injected through a capillary or needle into the co-flowing continuous phase (alginate solution) to form micro-capsules downstream of the circuit. The oil encapsulation using this gelation mechanism is a very recent approach and is still scarcely studied $[2,9,11]$. For example, Martins et al. (2017b) studied the different factors affecting emulsion stability, capsule size and membrane thickness. This study demonstrated the success of the production of (micro)-capsules based on the inverse gelation mechanism using droplets millifluidic. Monodisperse (micro)-capsules with sizes ranging from $1.4 \mathrm{~mm}$ down to $140 \mu \mathrm{m}$ were produced. The present work can be considered as a continuation of the work of Martins et al. (2017b), where the focus was on the final properties of capsules and more specifically on the mechanical properties and oil content of the capsules. In many cases, the capsules are subjected to mechanical stresses exerted by their environment that induce deformation and potential breakup. It is important to control the mechanical properties of capsules to ensure protection and/or release of the encapsulated substances under proper conditions and also to avoid breakup during processing. The present study focused on capsules made of a deformable membrane with an internal liquid core.

The objective of the present work is, therefore, to take advantages of the new droplets millifluidic/inverse gelation based process to produce core-shell alginate milli-capsules and to analyze the effect of varying curing time and cation concentration of the storage solution on the final properties of the obtained capsules, including oil content and mechanical properties.

The use of millifluidic devices paves the way to an integrative formulation of core- shell materials with a broad size range of monodisperse capsules (from $\mu \mathrm{m}$ to $\mathrm{mm}$ ) and new complex architectures. This should lead to the rapid emergence of new products in cosmetics or food, where the texture and visual aspect play a key role for sale.

\section{Materials and Methods}

\section{Materials}

Sodium alginate powder (Saltialgine S 60 NS) with a mannuronic $(\mathrm{M})$ to guluronic $(\mathrm{G})$ acid unit ratio $(\mathrm{M} / \mathrm{G})$ and a molar mass equal to 1.37 and $1.57 \times 10^{5} \mathrm{~g} / \mathrm{mol}$, respectively, was kindly donated by Cargill (France). Calcium chloride powder $\left(\mathrm{CaCl}_{2} \cdot 2 \mathrm{H}_{2} \mathrm{O}\right)$ (Panreac Quimica Sau, Spain), sunflower cooking oil (Associated Oil Packers, France), PGPR 90 (Danisco, France), Tween 20 (Sigma Aldrich, France) were used to prepare the $\mathrm{W} / \mathrm{O}$ emulsions. Other chemicals reagents were obtained from Sigma Aldrich (France).

\section{Methods}

\section{Preparation of Alginate and Calcium Chloride Solutions}

Ten grams of alginate powder was dissolved in $1 \mathrm{~L}$ of demineralized water using a magnetic stirrer. Tween 20 $(0.5 \%, v / v)$ was added to the alginate solution. The calcium chloride solution was prepared by dissolving $240 \mathrm{~g}$ of $\mathrm{CaCl}_{2}$. $2 \mathrm{H}_{2} \mathrm{O}$ in $1 \mathrm{~L}$ of demineralized water.

\section{Preparation of the W/O Emulsions}

Emulsions were prepared according to Martins et al. (2017b). One hundred millilitres of sunflower oil containing $0.96 \mathrm{~g}$ of surfactant (PGPR 90) was mixed using a high shear mixer (Ultra-Turrax T25, IKA, Germany) at $18000 \mathrm{rpm}$ for $1 \mathrm{~min}$. Sixty millilitres of calcium chloride solution $(240 \mathrm{~g} / \mathrm{L})$ was then added slowly and a new shear mixing at $18000 \mathrm{rpm}$ for 3 min was performed. 


\section{Capsules Production by Droplets Millifluidic}

A millifluidic device with a co-axial flow focusing geometry was used as described in [11] (Fig. 1, Supplementary data). The dispersed phase, a W/O emulsion freshly prepared (see "Preparation Of The W/O Emulsions" section) was pumped (Harvard Apparatus PHD 2000, France) through a fused silica capillary tube (interior diameter (ID) $530 \mu \mathrm{m}$ and outside diameter $(\mathrm{OD}) 660 \mu \mathrm{m})$ at a rate $\left(Q_{\mathrm{emul}}\right)$ of $4 \mathrm{~mL} / \mathrm{h}$. The continuous phase, an alginate solution added with Tween 20, was pumped through a Teflon tube (ID $=1.57 \mathrm{~mm}$ and $\mathrm{OD}=0.5 \mathrm{~mm})$ at a rate $\left(Q_{\mathrm{alg}}\right)$ of $10 \mathrm{~mL} / \mathrm{h}$. The $\mathrm{W} / \mathrm{O}$ emulsion and the alginate solutions co-flowed in the glass tube (ID $=2 \mathrm{~mm}, \mathrm{OD}=4 \mathrm{~mm}$ and length of $10 \mathrm{~cm}$ ). As the generation of capsules using W/O emulsion requires hydrophilic surfaces, the glass tube was previously immersed in a saturated-NaOH solution for $5 \mathrm{~min}$ at room temperature and rinsed using tap water [13].

$\mathrm{W} / \mathrm{O}$ emulsion drops were formed and dispersed in the continuous alginate phase. Calcium ions $\left(\mathrm{Ca}^{2+}\right)$ diffused from the $\mathrm{W} / \mathrm{O}$ emulsion drop cross-linking the alginate molecules. The capsules were collected in an alginate bath stirred at $50 \mathrm{rpm}$. After a curing time (time of contact between the capsules and the alginate solution) varying between 3 and $50 \mathrm{~min}$, the capsules were sieved, rinsed with distilled water, suspended in $\mathrm{Ca}^{2+}$ or $\mathrm{Na}^{+}$solution or in distilled water and stored at $4{ }^{\circ} \mathrm{C}$ until use.

\section{Characterization of the W/O Emulsions}

\section{Stability}

W/O emulsion stabilities were performed as described by Martins et al. (2015). Hundred millilitres of W/O emulsions were placed in tubes of $100 \mathrm{~mL}$ with graduation of $1 \mathrm{~mL}$. The emulsions were kept at ambient temperature $\left(20 \pm 2{ }^{\circ} \mathrm{C}\right)$ and visually inspected as a function of time in order to assess the critical time for which $1 \%$ of phase separation occurred (i.e. corresponding to $1 \mathrm{~mL}$ of phase separated liquid).

\section{Microscopic Observations}

W/O emulsions were diluted ten times in sunflower oil and observed under the microscope. The diluted emulsions were brought on a microscope slide using a capillary after which a cover slip was gently applied. Image acquisition was conducted using an optical microscope (Leica Microsystems, France). The size of $\mathrm{CaCl}_{2}$ solution droplets (dispersed phase) was determined by image analysis using the Image $1.47 \mathrm{v}$ freeware (National Institutes of Health, Bethesda, Maryland, USA). Measurements were carried out in triplicate with three repetitions. In other words, three $\mathrm{W} / \mathrm{O}$ emulsions of each formulation were analyzed by optical microscopy. Three different zones $(1.1 \times 1.5 \mathrm{~mm})$ for each sample were imaged and approximately one hundred droplets per zone were measured.

\section{Rheological Measurements}

The viscosity of sunflower oil, alginate solution and water inoil emulsions were investigated with a stress-controlled rheometer (AR-2000, TA Instruments, New Castle, DE) equipped with a Couette geometry (DIN 412). The temperature was controlled with a Peltier system. Dynamic viscosity and shear stress as a function of shear rate between 0.01 and $1000 \mathrm{~s}^{-1}$ were measured. Viscosity of alginate solution at $\mathrm{C}=$ $1 \%(w / v)$ gave $\eta=35.9 \pm 3.9 \mathrm{mPa}$.s while that of sunflower oil was of $70.2 \pm 1.7 \mathrm{mPa}$.s. W/O emulsion had a viscosity $\eta=$ $212.5 \pm 7.4$ mPa.s.

\section{Characterization of Capsules}

\section{Microscopic Observation}

External diameter (D), and membrane thickness (m) of capsules were performed under an optical microscope (Olympus IX51, France) equipped with a camera (Olympus DP70). A $40 \mathrm{X}$ objective was used to image microcapsules.
Fig. 1 Images of W/O emulsions as function of storage time
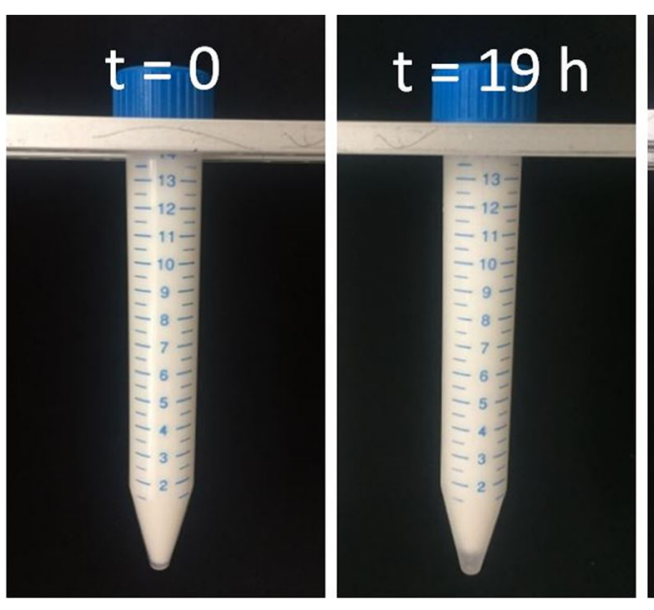

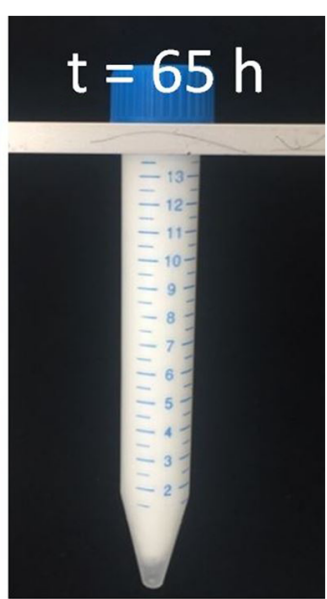


Dp controller software (version 2.1.1) was used for images acquisition. Shell thickness $\left(\mathrm{M}_{\mathrm{t}}\right)$ and capsules diameter (d) were therefore calculated from image analyses on 10 capsules per experimental condition using the imageJ $1.47 \mathrm{v}$ freeware (National Institutes of Health, Bethesda, Mayland, USA).

\section{Total Oil Content of the Capsules}

A TGA Q5000 instrument was used for the thermogravimetric analysis (TGA). An isothermal step at $60^{\circ} \mathrm{C}$ during $30 \mathrm{~min}$ was applied before the ramp up to $800{ }^{\circ} \mathrm{C}$ at $10{ }^{\circ} \mathrm{C} / \mathrm{min}$ under a nitrogen atmosphere $(25 \mathrm{~mL} / \mathrm{min})$. The capsules were dried $48 \mathrm{~h}$ at room temperature and $\mathrm{a}_{\mathrm{w}}=0.59$ $(\mathrm{NaBr})$ before TGA analyses. Oil content was determined by analyzing the thermograms of pure components and capsules.

\section{Mechanical Study}

A Dynamic Mechanical Analyzer (Rheometric Scientific, EEUU) equipped with a plate-plate geometry (diameter of $20 \mathrm{~mm}$ ) was used. The upper plate had a diameter of $20 \mathrm{~mm}$ and the normal force was measured as a function of the compression in a range between 0.001 and $20 \mathrm{~N}$. A force gap test was used to compress the capsules with a linear compression speed of $0.6 \mathrm{~mm} / \mathrm{min}$. The gap and the normal force being imposed were measured simultaneously at the upper plate. The surface Young modulus was calculated by a quantitative analysis of force-displacement curves at small deformations $[14,15]$. Five replicates were considered for each capsule.

\section{Statistical Analysis}

Data values obtained in the experiments were statistically analyzed by one-way analysis of variance (ANOVA) employing OriginLab 8.5 software. Differences between pairs of means were assessed on the basis of confidence intervals using the Tukey test. The least significance difference was $P<0.05$.

\section{Results and Discussion}

\section{Characterization of W/O Emulsions}

Emulsions containing sunflower oil, $\mathrm{CaCl}_{2}$ solution $(240 \mathrm{~g} / \mathrm{L})$ and PGPR 90 were prepared using a high shear mixer. The dispersed $\mathrm{W} / \mathrm{O}$ phase contained the calcium content that allows to crosslink the alginate and form the membrane of the capsules. Knowledge of the stability is very important as it is directly related with the $\mathrm{Ca}^{2+}$ release, and therefore the membrane formation.

PGPR 90 was chosen as emulsifier due to its low hydrophilic-lipophilic balance value $(\mathrm{HLB}=1.5)$, which made it prone to stabilize $\mathrm{W} / \mathrm{O}$ emulsions [16].
Several images of the emulsion in function of storage time, formed by dispersing calcium aqueous phase into the sunflower oil containing the surfactant PGPR 90, were shown in Fig. 1. Minimal phase separation and droplet coalescence occurred during storage over $24 \mathrm{~h}$. Martins et al. (2017b) studied the effect of surfactant concentration on the stability of the emulsions. By increasing emulsifier concentration, W/ $\mathrm{O}$ emulsions with stabilities increasing from 0.9 to $132 \mathrm{~h}$ were found. Marquez et al. [17] and Su et al. [18] found that higher the emulsifier concentration was, lower was the size of water droplets in W/O emulsion, increasing both its viscosity and stability.

In addition to visual inspections of the emulsion stability, the drops size of the dispersed aqueous phase was measured after 10 times dilution with oil by optical microscopy. Fig. 2a showed an image of a W/O emulsion stabilized by PGPR 90 at $6 \mathrm{~g} / \mathrm{L}$. High shear mixing led to emulsions with a narrow size distribution and a mean diameter of the dispersed aqueous phase drops of about $1.4 \mu \mathrm{m}$.

In order to confirm that it is a W/O emulsion, a drop of the emulsion was dispersed in water (Fig. 2b) and analyzed under optical microscopy. A double $\mathrm{W} / \mathrm{O} / \mathrm{W}$ emulsion was formed by an oil continuous phase and a first dispersed $\mathrm{CaCl}_{2}$ solution droplets internal phase surrounded by a second dispersed $\mathrm{CaCl}_{2}$ external phase.

\section{Characterization of Components by TGA}

Thermal degradation behavior of pure components that form the capsules (alginate, calcium and sunflower oil) was performed and analyzed by TGA up to $800{ }^{\circ} \mathrm{C}$, with the idea of identifying the degradation temperature of each component. Fig. 3 showed the TGA thermograms and derivative thermograms dTGA of sunflower oil, $\mathrm{CaCl}_{2}$ and alginate powders.

By analyzing the TGA of $\mathrm{CaCl}_{2} \cdot 2 \mathrm{H}_{2} \mathrm{O}$, a considerable weight loss was clearly observed between $25^{\circ} \mathrm{C}$ and $130^{\circ} \mathrm{C}$ that was ascribed to the endothermic removal of crystalline and loosely bound surface water, as it was also observed by Karunadasa et al. [19]. There was a first endothermic dehydration at around $130{ }^{\circ} \mathrm{C}$ accounted for the emergence of monohydrate calcium chloride $\left(\mathrm{CaCl}_{2} \cdot \mathrm{H}_{2} \mathrm{O}\right)$ (Fig. 3). A significant reduction in weight of calcium chloride was observed during the second endothermic dehydration (between 150 and $220^{\circ} \mathrm{C}$, dTGA curve, Fig. 3) that further ensured the complete removal of crystalline water from the material. Although the magnitude of second endothermic dehydration was significantly larger than the first one, it was concluded that the removal of crystalline water from the monohydrate was rather difficult compare to the dihydrate calcium chloride (Fig. 3, dTGA curve). This was a good indication of the strong association of crystalline water in monohydrate that requires a considerable amount of thermal energy to eliminate it from the monohydrate [19]. 
Fig. 2 Micrographs of (a) oil diluted $\mathrm{W} / \mathrm{O}$ emulsion (scale bar $25 \mu \mathrm{m})$ and (b) water diluted W/ $\mathrm{O}$ emulsion (scale bar $250 \mu \mathrm{m}$ ) resulting in the formation of a double $\mathrm{W} / \mathrm{O} / \mathrm{W}$ emulsion

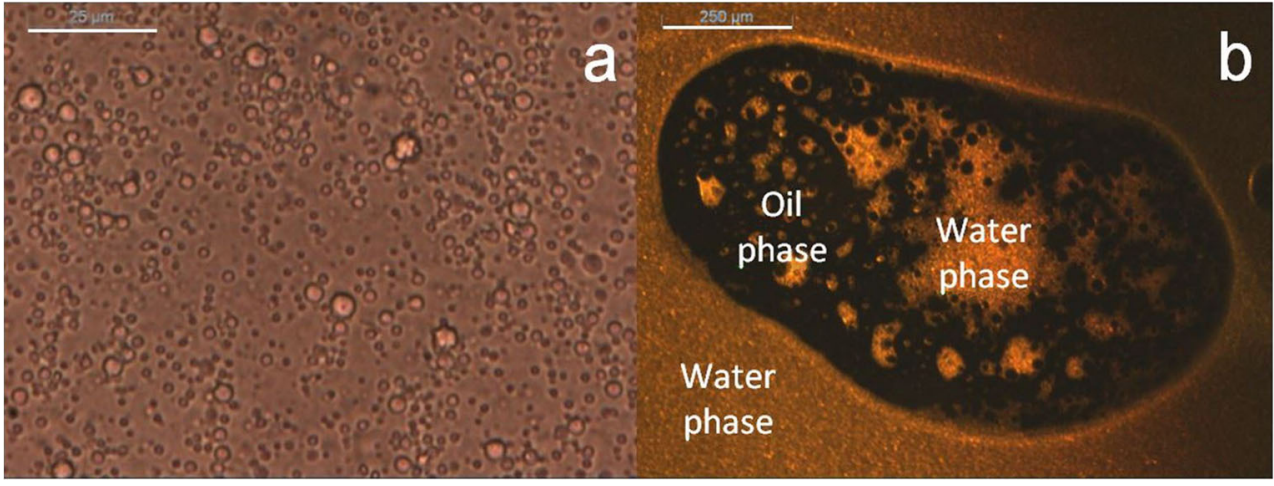

TGA/dTGA curves for sunflower oil displayed two thermal decomposition steps in the range of 300 to $510^{\circ} \mathrm{C}$, with no residue remaining at $800^{\circ} \mathrm{C}$ (see Fig. 3). It was observed that the first step ( 300 to $420^{\circ} \mathrm{C}$ ) corresponded to the decomposition of the polyunsaturated fatty acids. During heating, the triglycerides, which form 96 to $98 \%$ of the edible oils, produce volatile compounds, which are constantly removed by vapor generated during heating. These products (dimers, trimers, polymers) are formed principally by thermal reactions of unsaturated fatty acids, such as linoleic acid. The first step is the most important for the thermal stability of edible oils, because this is the step where decomposition of the unsaturated fatty acids begins. The thermal stability of sunflower oils is dependent on the composition of the fatty acids, as it is influenced by artificial antioxidants [20]. The beginning of oxidation in edible vegetable oils is characterized by absorption of oxygen through the fatty acid chain, subsequently forming the oxidation product as peroxides. This behavior is generally identified by an increase in the initial mass of the sample. The second step in the thermal decomposition of sunflower oils (420 to $520^{\circ} \mathrm{C}$ ) corresponds to the decomposition of monounsaturated fatty acids such as oleic acid and saturated fatty acids, such

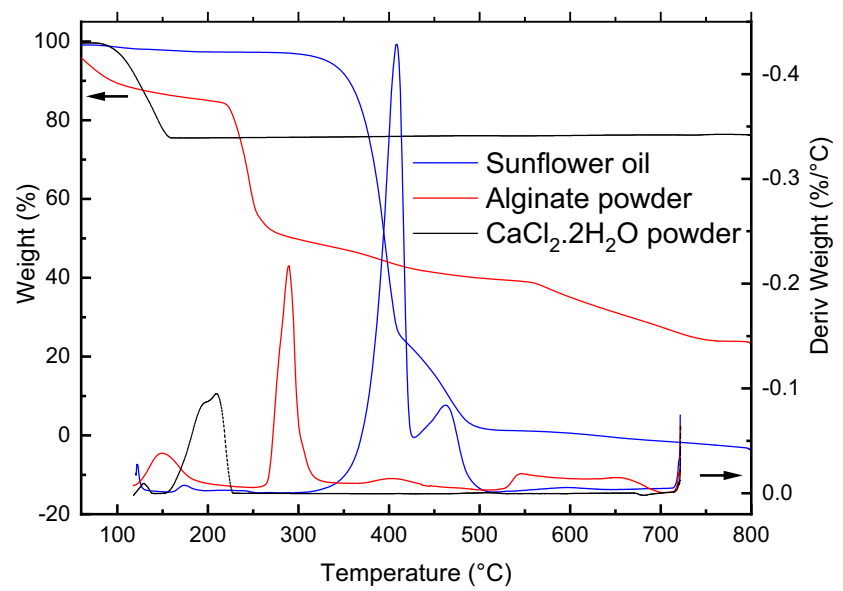

Fig. 3 Thermogravimetric analyses of sunflower oil, alginate and calcium chloride powders used to prepare capsules as palmitic acid. During this reaction, the double bonds are broken, causing the triglyceride molecules in the edible vegetable oils to become saturated [20].

Figure 3 also showed TGA and dTGA curves for sodium alginate. It is shown that the salt decomposed by dehydration followed by degradation to $\mathrm{Na}_{2} \mathrm{CO}_{3}$ and carbonized material that decomposed slowly from 550 to $750{ }^{\circ} \mathrm{C}$ in $\mathrm{N}_{2}$ (Fig. 3), as also noticed by other authors $[21,22]$.

Taking into account that alginate content in the dried capsules as well as the degradation peaks observed by dTGA curves are negligible, compared to the sunflower oil alone, it was considered that temperature range of the oil degradation did not overlap with those of alginate and $\mathrm{CaCl}_{2}$ pure components. By this way, it was therefore possible to use this technique to determine the oil content of the wet and dried capsules between 300 and $510{ }^{\circ} \mathrm{C}$.

\section{Microcapsules Formation}

Based on Martins et al. (2017b) previous results, the mechanism of capsule formation would occur in three steps:

I- Emulsion drops characterized by a continuous oil phase containing $\mathrm{CaCl}_{2}$ solution droplets contacted the alginate solution

II- $\mathrm{CaCl}_{2}$ solution droplets near the oil-alginate solution interface were able to migrate from the emulsion to the alginate phase by a mechanism of diffusion/permeation through the oil layer [23]

III- $\mathrm{Ca}^{2+}$ ions cross-linked the alginate chains resulting in the formation of a membrane.

\section{Effect of Curing Time}

W/O emulsions containing $90 \mathrm{~g} / \mathrm{L}$ of $\mathrm{CaCl}_{2}$ and $6 \mathrm{~g} / \mathrm{L}$ of PGPR 90 were co-flowed with the alginate-Tween 20 continuous phase in order to generate monodisperse $\mathrm{W} / \mathrm{O}$ emulsion drops that finally reached the alginate bath. These capsules 
were kept in contact with the alginate bath by increasing curing time from 3 to $50 \mathrm{~min}$. After these curing times, capsules were filtered, rinsed with distilled water and stored in a $\mathrm{CaCl}_{2}$ solution $(15 \mathrm{~g} / \mathrm{L})$ at $4{ }^{\circ} \mathrm{C}$ before microscopy observations.

Size of Capsules and Membrane Thickness Microscopic observations revealed that spherical capsules with a well-defined alginate membrane were collected in the alginate bath whatever the curing time (Fig. 4).

Figure 5 showed the dependence of capsule diameter and membrane thickness with curing time. The average diameter of alginate capsules ranged from 1.9 to $2.6 \mathrm{~mm}$ depending on curing time (significant differences at $p<0.05$ ), with a size polydispersity lower than $10 \%$ (data not shown). Other authors also found that microcapsules produced using microfluidics had extremely narrow size distributions [24]. Using droplets millifluidic process, capsule size depends on droplet dimension before getting into contact with the alginate phase, droplet dimension depending on both the internal diameter of the Teflon tube (which was constant and equal to $1.57 \mathrm{~mm}$ throughout the experimental assays) and the dispersed over continuous flow rates ratio (also constant and equal to 0.4 ).

Membrane thickness measurements (made from pictures obtained by optical microscopy) showed a curing timedependent thickness of alginate capsules which increased with curing time (from $98 \pm 28$ to $306 \pm 21 \mu \mathrm{m}$ at 3 and $45 \mathrm{~min}$, respectively) (significant differences at $p<0.05$ ) (see Fig. 5). The increase of membrane thickness was significant at low curing times and reached a pseudo-plateau at high curing times. The capsules reached therefore the maximum of membrane thickness after $30 \mathrm{~min}$ of curing time. This result was consistent with the increase of diffusion resistance and the decrease of calcium chloride concentration in time [25]. Blandino et al. [26] obtained nearly the same evolution for the thickness of gel layer capsules as a function of time for an alginate-CMC capsule system where thickness was measured by cutting the capsules into halves and examining the membranes with a microscope.

From Figs. 4 and 5, it was concluded that capsule diameter and membrane thickness were linearly dependent on curing time; in addition, membrane thickness reached a plateau at high curing times due to restricted calcium diffusion. Martins et al. [11] checked that the emulsion drop surface was surrounded by an oily layer that limited the contact of the $\mathrm{CaCl}_{2}$ solution droplets with the external media. This external oil layer could act as a barrier hindering the release of aqueous $\mathrm{CaCl}_{2}$ droplets during the capsule production.

Capsules Oil Content In this study, droplets millifluidic was used as a rapidly expanding technology with a unique ability to "package" materials in the form of millicapsules, and a natural polysaccharide from brown seaweed as a stable container of sunflower oil. Therefore, it was very important to ascertain the capacity of the polymeric matrix to hold the bioactive compounds.

Oil content was around $80 \%$ for all the analyzed dried millicapsules, a content quite high compare to other encapsulation processes based on the external and on the internal gelation mechanisms [27]. Once the emulsion was in contact with alginate, the process of membrane formation occurred but the oil was already encapsulated. As the contribution of the membrane weight was negligible with respect to the oil content, the increase in the curing time did not represent a substantial change of the final core content (Fig. 2, Supplementary data). This was the main reason why, despite the high reproducibility of the method to produce monodisperse core-shell capsules, the oil content was always constant.

Mechanical Properties of Capsules Mechanical behavior is a very important characteristic, as capsules or beads have to withstand mechanical stress caused by shear forces, compression or osmotic pressure, during the manufacture of the food product, packaging, transport, storage, handling and consumption. In particular, mechanical stiffness of alginate gel millicapsules, controlled by the strength and number of cross-links between the polymer chains, influences the permeability of the capsules, property highly important for solutes diffusion in cell encapsulation [28].

Numerous methods exist to determine the mechanical properties of capsules [29]. A well-established method consists in uniaxial compression of a single capsule between two plates and recording the force-displacement curve. Compression experiments are generally sufficiently sensitive to characterize the mechanical behavior of liquid-filled alginate capsules.

Elastic characteristics such as Young modulus are calculated from the initial slope of the force-displacement curve by means of different approaches (e.g. Hertz model) [15, 24, 29, 30]. The advantage of single-bead measurement consists in detailed information of a single object and variations between

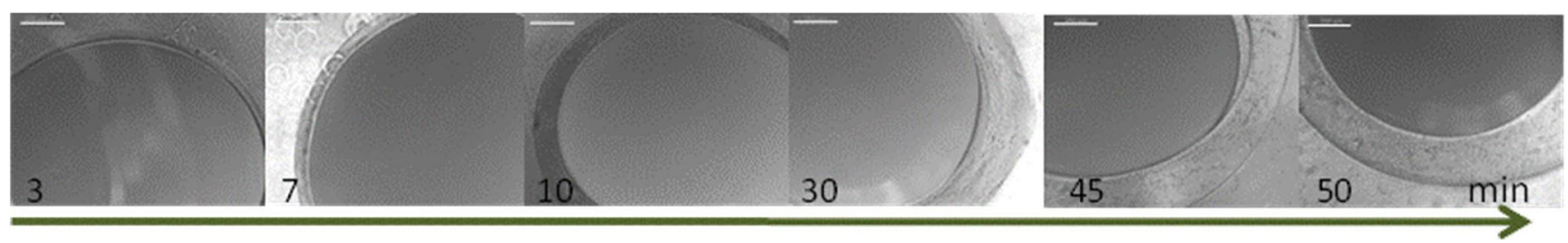

Fig. 4 Micrographs of wet capsules as function of curing time. Scale bar $250 \mu \mathrm{m}$ 
Fig. 5 Diameter $\mathrm{d}(\mathrm{mm})$ and membrane thickness Mt. $(\mu \mathrm{m})$ of wet capsules as function of curing time. Solid line corresponded to the fitting of the data by a linear function; dotted line was just eyeguide. At the 0.05 level, the populations means were significantly different

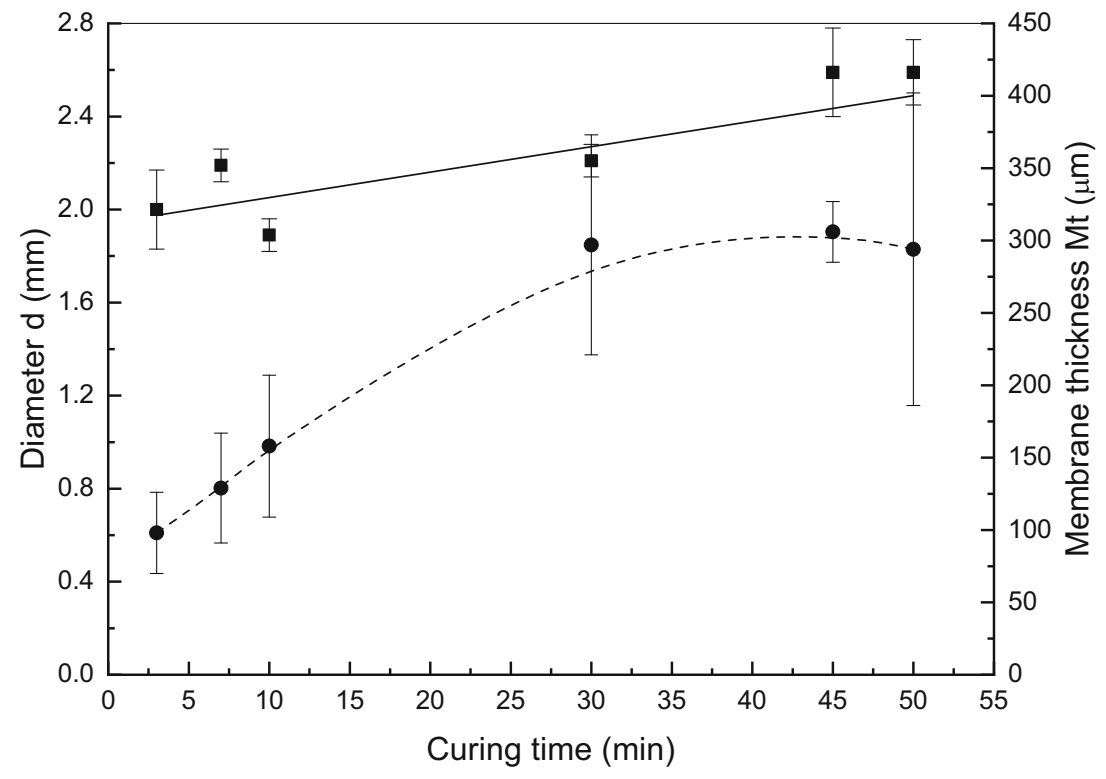

beads of one production batch can be thoroughly analyzed. Otherwise, it is time consuming to collect substantial, statistical significant data [24, 31].

Alginate capsules are sensitive to deformations that may lead to their rupture or to undesirable early release of their content. It was demonstrated from the analyses of forceindentation curves obtained by AFM that alginate microspheres, beads and capsules had almost a pure elastic behavior [32]. Surface Young modulus, or two-dimensional Young modulus, is therefore an interesting parameter to quantify mechanical stability as it describes the elastic properties of the capsules. From Eq. (1), compression curves at small deformations were linearly fitted in order to extract the twodimensional (or surface) Young modulus Es under point loading close to the pole [15]:

$F=\frac{4 E s m}{a \sqrt{3\left(1-v s^{2}\right)}} d D$

In this equation, $d D$ is the capsule displacement, $F$ the measured force, Es the surface Young modulus, $m$ the membrane thickness, $a$ the radius of the capsule and vs the surface Poisson ratio for which a value of $1 / 3$ was assumed according to [25]. Other more complicated methods of resolution by solving numeric calculations were presented in further citations [33, 34]. It was therefore important to recall that Eq. 1 only holds for spherical capsules in the very small deformations regime.

A typical force $(\mathrm{F})$ versus displacement (D) curve from compression of single dry and wet alginate capsules were shown in Fig. 6. As expected, the drying step induced an approximately ten-fold reduction of the membrane thickness due to water loss and, consequently, a huge increase of the surface Young modulus was noticed (see Table 1 and Fig. 6).
Figure 7 summarized surface Young modulus values of wet alginate capsules in function of curing time (calculated by linear regression from compression curves at small displacements). Surface Young moduli (significant differences at $p<0.05)$ approximately two-fold decreased with increasing curing time, result in apparent contradiction with the increase of membrane thickness with curing time. Surface Young modulus values were in the same order of magnitude that those obtained by Leick et al. [25] for alginate capsules obtained from two types of alginate with different guluronic acid content: $6.5 \mathrm{~N} / \mathrm{m}$ and $32.9 \mathrm{~N} / \mathrm{m}$, for the higher and lower content of guluronic acid, respectively. From another study, Leick et al. [35] found surface Young moduli of 10 and $5 \mathrm{~N} / \mathrm{m}$ for pure alginate and alginate/PLL capsules taking a Poisson ratio of zero, values consistent with the assumption of a lower cross-linking degree of the alginate/PLL composite capsules.

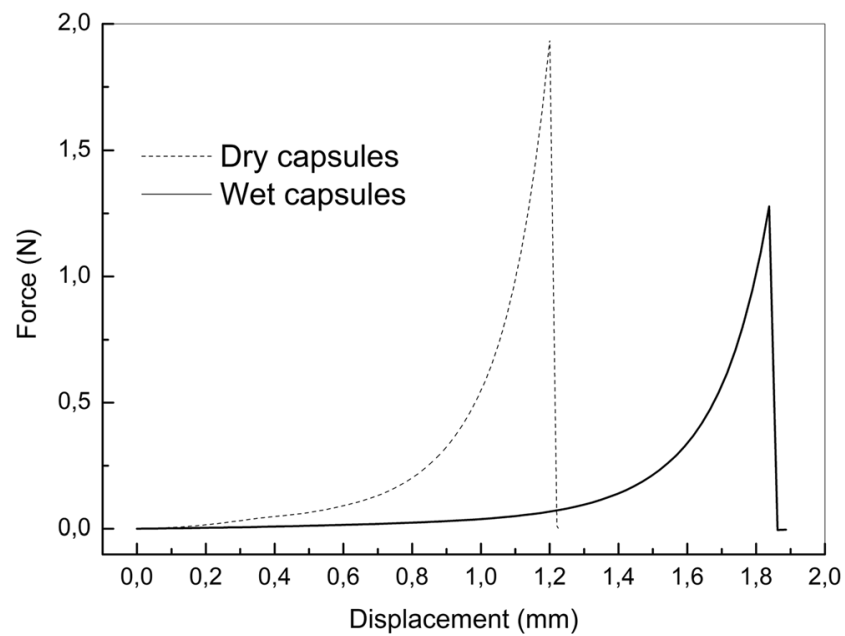

Fig. 6 Compression behavior of wet and dry capsules. Curing time $=$ $30 \mathrm{~min}$ 
Table 1 Mechanical properties of wet and dry capsules. Curing time $=30 \mathrm{~min}$. conditions

\begin{tabular}{llllll}
\hline & $\begin{array}{l}\text { Diameter D } \\
(\mathrm{mm})\end{array}$ & $\begin{array}{l}\text { Membrane thickness Mt } \\
(\mu \mathrm{m})\end{array}$ & D/Mt & \multicolumn{2}{l}{$\begin{array}{l}\text { Surface Young modulus } \\
(\mathrm{N} / \mathrm{m})\end{array}$} \\
\hline Wet capsules & $2.21 \pm 0.07$ & $297 \pm 76$ & $7.4 \pm 0.3$ & $26.1 \pm 1.8$ & $\begin{array}{l}\text { Force at break } \\
(\mathrm{N})\end{array}$ \\
Dry capsules & $1.85 \pm 0.14$ & $27 \pm 12^{*}$ & $60.1 \pm 5.9$ & $613 \pm 163$ & $1.15 \pm 0.27$ \\
\hline
\end{tabular}

* Membrane thickness was estimated from other capsules that were obtained and dried in the same

More interestingly, each additional electrolyte adsorption layer (PLL or alginate) gave roughly an increase of the surface Young modulus of about $5 \mathrm{~N} / \mathrm{m}$ for the investigated alginate/ PLL/alginate capsule system under the used preparation conditions. Messaoud et al. [36] investigated the influence of $\mathrm{pH}$ for alginate capsules, and they obtained surface Young moduli ranging from 14.9 to $22 \mathrm{~N} / \mathrm{m}$ at $\mathrm{pH} 7$ and $\mathrm{pH} 2$, respectively, indicating that a decrease in $\mathrm{pH}$ resulted in a stiffer alginate membrane. The same $\mathrm{pH}$-dependence thickness of composite pectinate/shellac capsules was found by Leick et al. [37]. The dependence of the $\mathrm{pH}$ value for composite capsules on the deformation was also consistent with variations of the membrane thickness. Membranes prepared with additional shellac seemed to be thinner but stiffer. Furthermore, at the lowest $\mathrm{pH}$ value, the highest amount of precipitated shellac led to the strongest inhibition of calcium ion diffusion and therefore to the thinnest membranes.

Figure 8 displayed the evolution of the surface Young modulus with the capsule dimensions. Apart from the slight decrease of surface Young modulus with the increase of wet capsule diameter (Fig. 8a) and the linear decay with membrane thickness (Fig. 8b), it was noticed that the surface

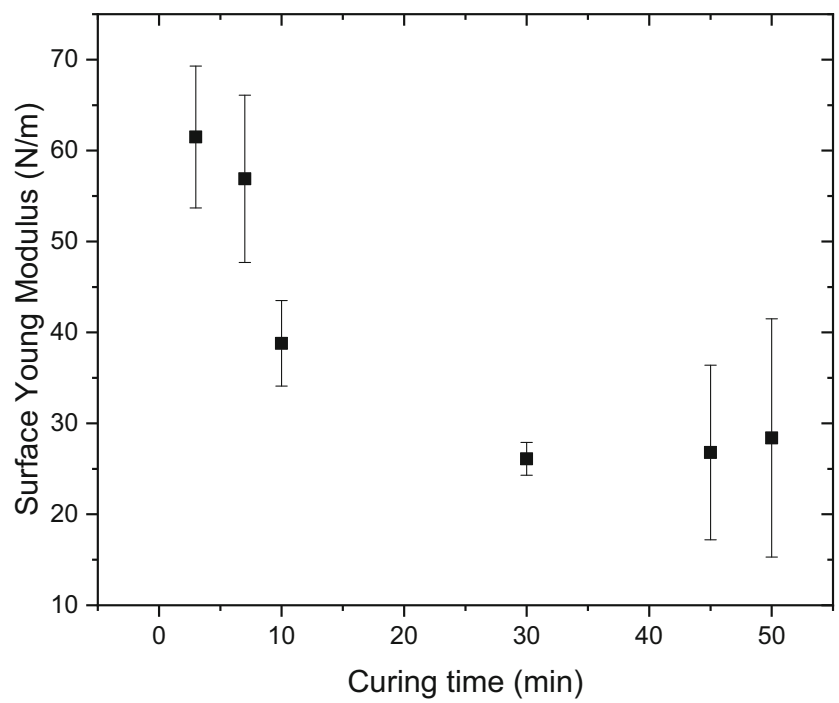

Fig. 7 Surface Young modulus $(\mathrm{N} / \mathrm{m})$ of wet capsules as function of curing time. At the 0.05 level, the populations means were significantly different
Young modulus linearly increased with the diameter / thickness ratio of capsules (Fig. 8c). Rachik et al. [14] reported that the increase in membrane thickness was linked to an increase in intrinsic membrane rigidity as it was expected that the density of crosslinking was larger in thicker membranes. Consequently, the surface Young modulus Es that measures the whole ability of the membrane to deform upon deformation increased. Contrary, in our study, surface Young modulus ranged from 68 to $21 \mathrm{~N} / \mathrm{m}$ at 3 and $50 \mathrm{~min}$, respectively, (see Table 1), indicating that an increase of curing time led to an increase of membrane thickness (see Fig. 8b) and to a decrease of the mechanical properties (lower surface Young modulus $E_{s}$ values) resulting in softer alginate membranes. This decrease of the two-dimensional modulus could be explained by a higher hydration level of the membrane leading therefore to a decrease of the crosslinking degree, i.e. the density of ionic bonds between $\mathrm{Ca}^{2+}$ and alginate would be smaller in the thicker membrane due to water uptake. Following this hypothesis, calcium content from the W/O droplets quickly diffused from the emulsion-core to the alginate solution and remained constant with time. This phenomenon was clearly seen on Figs. $8 \mathrm{~b}$ and $\mathrm{c}$ where a linear decrease was noticed for the surface Young modulus with the increase of membrane thickness and diameter / thickness ratio. This result therefore gave more confidence to the hypothesis of Martins et al. [11] who clearly identified by optical microscopy that the emulsion drop surface was surrounded by an oily layer that limited the contact of $\mathrm{CaCl}_{2}$ solution droplets with alginate phase. This external oil layer therefore acted as a barrier hindering the release of aqueous $\mathrm{CaCl}_{2}$ droplets during curing time.

\section{Effect of Cation Concentration}

In order to understand the effect of the storage solution on both membrane thickness and surface Young modulus, capsules with a curing time of $30 \mathrm{~min}$ in an alginate bath were stored in $\mathrm{NaCl}$ solution (1.5\%wt) and several $\mathrm{CaCl}_{2}$ solutions at concentrations ranging from 0 to $1.5 \%$ wt.

Microscopic observations were performed during a $48 \mathrm{~h}$ period to see the evolution of membrane thickness (see Fig. 9) (significant differences at $p<0.05$ ). The first important observation was that membrane thickness was higher when capsules were stored in distilled water contrary to $\mathrm{CaCl}_{2}$ 

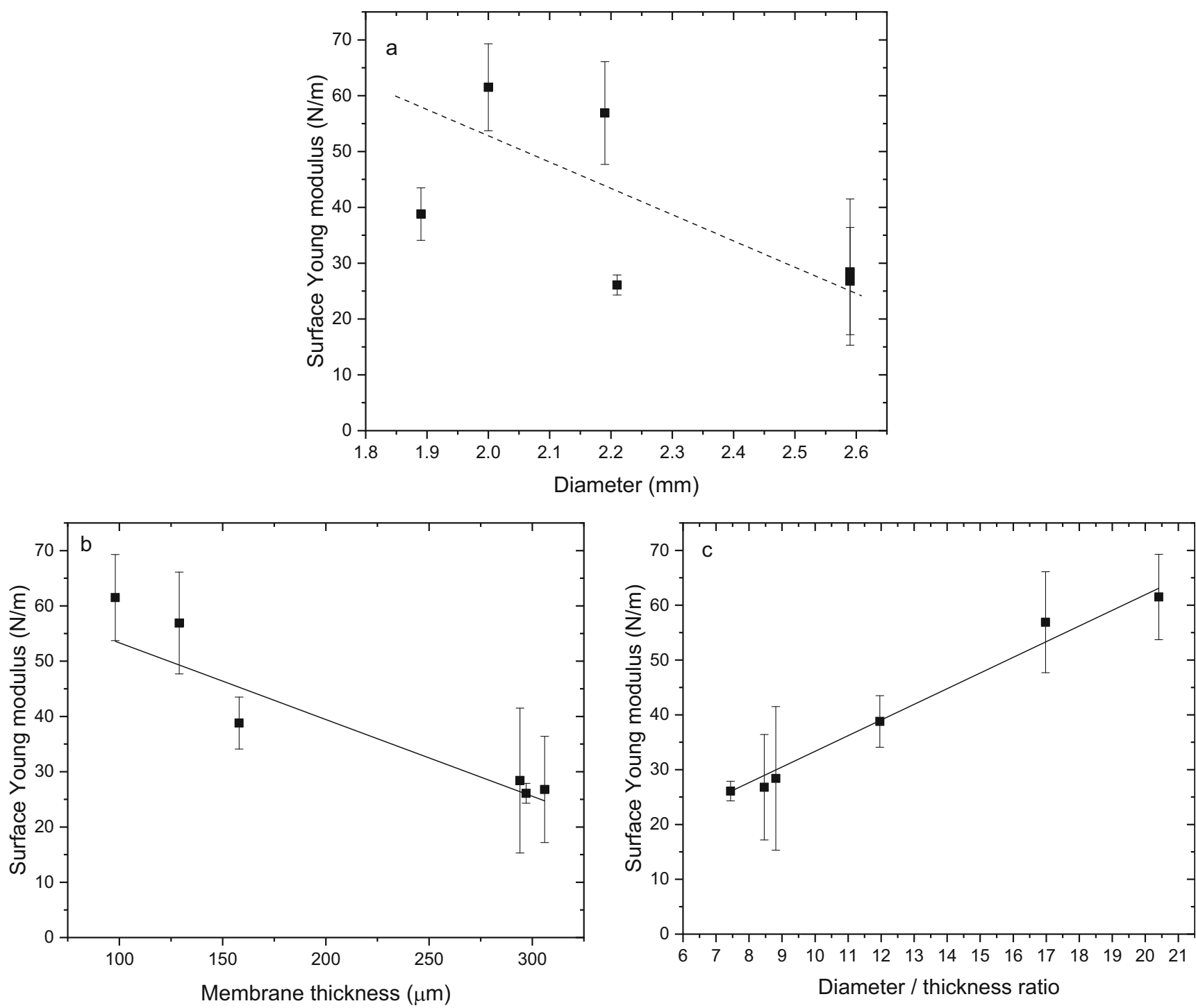

Fig. 8 Evolution of the surface Young modulus with wet capsule dimensions: (a) diameter; (b) membrane thickness and (c) diameter/thickness ratio

solutions, result in agreement with the swelling of alginate membrane in time. After $24 \mathrm{~h}$ of storage in $\mathrm{CaCl}_{2}$ solution, membrane thickness reached a plateau whatever $\mathrm{CaCl}_{2}$ concentration (Fig. 9). This result was in accordance with the absence of diffusion of calcium ions from inside to the outside of the capsules and conversely hindering the growth of alginate membrane in time. Finally, the storage of capsules in $\mathrm{NaCl}$ solution led to a huge increase of membrane thickness in time, result in accordance with the competition of calcium and sodium ions for alginate cross-linking and the resulting swelling of alginate membrane due to the loss of calcium ions in the cross-links. The membrane thickness measured at $48 \mathrm{~h}$ was used to evaluate the mechanical properties immediately after the microscopic observations.

Table 2 showed the surface Young modulus values obtained from the analyses of the force displacement curves. Surface
Young modulus values were constant with an average value of $35 \mathrm{~N} / \mathrm{m}$ whatever the calcium concentration used for the storage of alginate capsules, result in agreement with the constant value of membrane thickness (Mt $\sim 360.3 \mu \mathrm{m}$ ).

In order to eliminate the influence of membrane thickness on the surface Young modulus and to facilitate the comparison between the different storage conditions, Table 2 also showed a normalized Surface Young modulus defined as Es/Mt. Even if it was confirmed that Es/Mt. was constant whatever the calcium concentration used for capsules storage with Es/Mt. $\sim 0.099$, it was noticed that Es/Mt. two-fold decreased when capsules were stored in distilled water and more important thirty three-fold decreased when capsules were stored in $\mathrm{NaCl}$. The increase of membrane thickness according to the decrease of Es/Mt. was of 33\% in water and of $107 \%$ in $\mathrm{NaCl}$. Swelling process of alginate membrane could be evoked to 


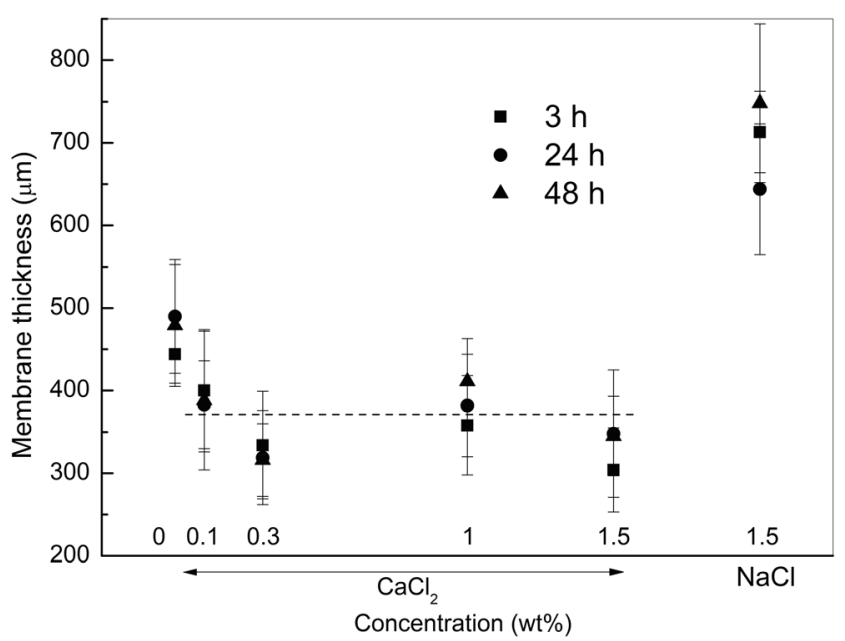

Fig. 9 Evolution of the membrane thickness after different storage times in distilled water, $\mathrm{CaCl}_{2}$ or $\mathrm{NaCl}$ solutions. Curing time in alginate solution $=30 \mathrm{~min}$. At the 0.05 level, the populations means were significantly different

explain the increase of membrane thickness and therefore the decrease of surface Young modulus depending on storage conditions. This swelling process would be considerably favored in presence of sodium salt compare to distilled water in particular due to the competition of sodium and calcium ions for the guluronic acid residues on alginate chains favoring the large decrease of cross-linking density in the alginate network and the huge increase of water uptake within the membrane. Authors recently clearly demonstrated, using spinning drop techniques, capsule squeezing experiments and interfacial shear rheology, changes in the mechanical properties of alginate membrane after storage of capsules in calcium or sodium salt solutions [38]. For instance, surface Young modulus determined by compression experiments decreased from 41 to $6.0 \mathrm{~N} / \mathrm{m}$ when capsules were stored in calcium and sodium salt solutions, respectively. This effect was ascribed to changes of the cross-linking density and therefore a reduction of cross-linking density due to ion exchange in the case of sodium salt. It was also found recently that sugar concentrations above $15 \%(\mathrm{wt})$ reduced extensibility of alginate molecules and lead to a more open or less connected gel network with aggregated alginate strands [39]. In addition, authors also demonstrated the high swelling rate of alginate capsules without sugar in presence of simulated intestinal fluid, fluid containing sodium hydroxide and potassium phosphate. The effect of sodium salt could be similar to sugar or intestinal fluid by changing the alginate network and in particular pore diameter allowing a higher uptake of water in the membrane. Pore diameters ranging from 2.52 to $3.94 \mathrm{~nm}$ were recently reported, using low temperature $\mathrm{N} 2$ adsorption-desorption analysis, depending on alginate sample and sodium content [40].

\section{Conclusions}

Stable W/O emulsions with a narrow size distribution were obtained by homogenization using PGPR 90 as surfactant. Spherical millimetric capsules were successfully obtained by inverse gelation using droplets-based millifluidic. The effect of curing time and cation concentration on the oil content, structure and mechanical properties of capsules was analyzed. Alginate membrane thickness increased with curing time in the collecting alginate bath until a plateau was reached, in close relation with the presence of an oily layer surrounded the surface of W/O emulsion drops therefore limiting the contact of $\mathrm{CaCl}_{2}$ solution droplets with alginate phase. This external oil layer therefore acted as a barrier hindering the release of aqueous $\mathrm{CaCl}_{2}$ droplets during curing time. Compression experiments on individual capsules revealed that alginate membrane thickness was inversely related to its mechanical properties, i.e. the thicker membrane, the lower surface Young modulus. This result was explained in terms of enhanced swelling properties of alginate membrane with curing time or storage conditions. Drying capsules led to much more resistant membranes due to

Table 2 Surface Young modulus values of capsules after $48 \mathrm{~h}$ storage in distilled water, $\mathrm{CaCl}_{2}$ or $\mathrm{NaCl}$ solutions. Curing time in alginate solution $=30 \mathrm{~min}$

\begin{tabular}{|c|c|c|c|c|c|}
\hline $\begin{array}{l}\text { Storage solution. } \\
(\mathrm{wt} \%)\end{array}$ & $\begin{array}{l}\text { Diameter } \\
(\mathrm{d}, \mathrm{mm})\end{array}$ & Membrane thickness (Mt, $\mu \mathrm{m})$ & $\mathrm{d} / \mathrm{Mt}$ & $\begin{array}{l}\text { Surface Young modulus } \\
(\text { Es, N/m) }\end{array}$ & $\begin{array}{l}\mathrm{Es} / \mathrm{Mt} \\
(\mathrm{N} / \mathrm{m} / \mu \mathrm{m})\end{array}$ \\
\hline Distilled Water & $2.27 \pm 0.20^{\mathrm{a}, \mathrm{c}}$ & $479 \pm 74^{\mathrm{a}}$ & $4.7 \pm 0.3^{\mathrm{a}, \mathrm{d}}$ & $23.4 \pm 2.64^{\mathrm{a}}$ & 0.049 \\
\hline $\mathrm{CaCl}_{2} 0.1$ & $2.43 \pm 0.17^{\mathrm{a}, \mathrm{b}, \mathrm{c}}$ & $388 \pm 84^{\mathrm{a}, \mathrm{b}, \mathrm{c}}$ & $6.3 \pm 1.7^{\mathrm{a}, \mathrm{b}, \mathrm{c}}$ & $28.7 \pm 4.6^{\mathrm{a}}$ & 0.073 \\
\hline $\mathrm{CaCl}_{2} 0.3$ & $2.33 \pm 0.18^{\mathrm{a}, \mathrm{b}, \mathrm{c}}$ & $316 \pm 44^{\mathrm{b}, \mathrm{c}}$ & $7.4 \pm 1.4^{\mathrm{b}, \mathrm{c}}$ & $39.5 \pm 3.3^{\mathrm{b}, \mathrm{c}}$ & 0.125 \\
\hline $\mathrm{CaCl}_{2} 1$ & $2.40 \pm 0.19^{\mathrm{a}, \mathrm{b}, \mathrm{c}}$ & $392 \pm 61^{\mathrm{a}, \mathrm{b}, \mathrm{c}}$ & $6.1 \pm 1.1^{\mathrm{a}, \mathrm{b}, \mathrm{c}}$ & $29.1 \pm 6.6^{\mathrm{a}, \mathrm{b}}$ & 0.074 \\
\hline $\mathrm{CaCl}_{2} 1.5$ & $2.60 \pm 0.14^{\mathrm{b}}$ & $345 \pm 48^{\mathrm{c}}$ & $7.5 \pm 1.1^{\mathrm{c}}$ & $42.6 \pm 6.9^{c}$ & 0.123 \\
\hline $\mathrm{NaCl} 1.5$ & $2.11 \pm 0.14^{\mathrm{c}}$ & $748 \pm 96^{\mathrm{d}}$ & $2.8 \pm 0.5^{\mathrm{d}}$ & $2.3 \pm 0.1^{\mathrm{d}}$ & 0.003 \\
\hline
\end{tabular}

a,b,c,d Different letters in the same column indicate significant differences among the different storage solutions $(p<0.05)$ 
the loss of water. Oil loading of $80 \mathrm{wt} \%$ was obtained for dry capsules whatever the conditions used.

Acknowledgements We kindly acknowledge the supply of PGPR 90 by Danisco (France), the supply of alginate by Cargill (France), the technical assistance of Jean-Eudes Megret for compression experiments, and the financial support of one author (Mariana Pereda) by the National Research Council of Republic Argentina (CONICET) through the program "Becas en el Exterior para Jóvenes Investigadores del CONICET" (Argentina).

\section{References}

1. B. Lupo, A. Maestro, M. Porras, J.M. Gutiérrez, C. González, Preparation of alginate microspheres by emulsification/internal gelation to encapsulate cocoa polyphenols. Food Hydrocoll. 38, 5665 (2014)

2. E. Martins, D. Renard, J. Davy, M. Marquis, D. Poncelet, Oil core microcapsules by inverse gelation technique. J. Microencapsul. 32(1), 86-95 (2015)

3. S.J. Risch, G.A.A. Reineccius, Flavor Encapsulation, ACS SymposiumSeries 370 (American Chemical Society, Washington, DC, 1988)

4. M. Jin, Y. Zheng, Q. Hu, Preparation and characterization of bovine serum albumin alginate/chitosan microspheres for oral administration. Asian J. Pharm. Sci. 4(4), 215-220 (2009)

5. K. Ziani, Y. Fang, D.J. McClements, Encapsulation of functional lipophilic components in surfactant-based colloidal delivery systems: vitamin E, vitamin D, and lemon oil. Food Chem. 134(2), 1106-1112 (2012)

6. C. Ouwerx, N. Velings, M.M. Mestdagh, M.A.V. Axelos, Physicochemical properties and rheology of alginate gel beads formed with various divalent cations. Polymer Gels and Networks 6(5), 393408 (1998)

7. D. Poncelet, V. Babak, C. Dulieu, A. Picot, A physico-chemical approach to production of alginate beads by emulsificationinternal ionotropic gelation. Colloids Surf. A Physicochem. Eng. Asp. 155(2-3), 171-176 (1999)

8. D. Quong, R.J. Neufeld, G. Skjåk-Bræk, D. Poncelet, External versus internal source of calcium during the gelation of alginate beads for DNA encapsulation. Biotechnol. Bioeng. 57(4), 438$446(1998)$

9. S. Abang, E.S. Chan, D. Poncelet, Effects of process variables on the encapsulation of oil in ca-alginate capsules using an inverse gelation technique. J. Microencapsul. 29(5), 417-428 (2012)

10. E. Martins, D. Poncelet, D. Renard, A novel method of oil encapsulation in core-shell alginate microcapsules by dispersion-inverse gelation technique. React. Funct. Polym. 114, 49-57 (2017a)

11. E. Martins, D. Poncelet, M. Marquis, J. Davy, D. Renard, Monodisperse core-shell alginate (micro)-capsules with oil core generated from droplets millifluidic. Food Hydrocoll. 63, 447$456(2017 b)$

12. J.-Y. Wang, Y. Jin, R. Xie, J.-Y. Liu, X.-J. Ju, T. Meng, L.-Y. Chu, Novel calcium-alginate capsules with aqueous core and thermoresponsive membrane. J. Colloid Interface Sci. 353, 61-68 (2011)

13. A. Schmit, L. Courbin, M. Marquis, D. Renard, P. Panizza, A pendant drop method for the production of calibrated double emulsions and emulsion gels. Rsc Advances 4(54), 28,504-28,510 (2014)

14. M. Rachik, D. Barthes-Biesel, M. Carin, F. Edwards-Levy, Identification of the elastic properties of an artificial capsule membrane with the compression test: effect of thickness. J. Colloid Interface Sci. 301(1), 217-226 (2006)
15. A. Fery, R. Weinkamer, Mechanical properties of micro-and nanocapsules: Single-capsule measurements. Polymer 48(25), 7221-7235 (2007)

16. A.M. Al-Sabagh, The relevance HLB of surfactants on the stability of asphalt emulsion. Colloids Surf. A Physicochem. Eng. Asp. 204(1-3), 73-83 (2002)

17. A.L. Márquez, A. Medrano, L.A. Panizzolo, J.R. Wagner, Effect of calcium salts and surfactant concentration on the stability of waterin-oil (w/o) emulsions prepared with polyglycerol polyricinoleate. J. Colloid Interface Sci. 341(1), 101-108 (2010)

18. J.H. Su, J. Flanagan, Y. Hemar, H. Singh, Synergistic effects of polyglycerol ester of polyricinoleic acid and sodium caseinate on the stabilisation of water-oil-water emulsions. Food Hydrocoll. 20(2-3), 261-268 (2006)

19. K.S. Karunadasa, C.H. Manoratne, H.M.T.G.A. Pitawala, R.M.G. Rajapakse, Relative stability of hydrated/anhydrous products of calcium chloride during complete dehydration as examined by high-temperature X-ray powder diffraction. J. Phys. Chem. Solids 120, 167-172 (2018)

20. A. Souza, J.C. Santos, M.M. Conceição, M.C. Silva, S. Prasad, A thermoanalytic and kinetic study of sunflower oil. Braz. J. Chem. Eng. 21(2), 265-273 (2004)

21. Zhao, Y., Huang, Z., Zhang, J., Wu, W., Wang, M., \& Fan, L. (2010). Thermal Degradation of Sodium Alginate-Incorporated Soy Protein Isolate/Glycerol Composite Membranes.

22. J.P. Soares, J.E. Santos, G.O. Chierice, E.T.G. Cavalheiro, Thermal behavior of alginic acid and its sodium salt. Eclética Química 29(2), 57-64 (2004)

23. A.K. Pawlik, Duplex emulsions for healthy foods (Doctoral dissertation, University of Birmingham, 2012)

24. A. Gray, S. Egan, S. Bakalis, Z. Zhang, Determination of microcapsule physicochemical, structural, and mechanical properties. Particuology 24, 32-43 (2016)

25. S. Leick, S. Henning, P. Degen, D. Suter, H. Rehage, Deformation of liquid-filled calcium alginate capsules in a spinning drop apparatus. Phys. Chem. Chem. Phys. 12(12), 2950-2958 (2010)

26. A. Blandino, M. Macias, D. Cantero, Formation of calcium alginate gel capsules: influence of sodium alginate and $\mathrm{CaCl} 2$ concentration on gelation kinetics. J. Biosci. Bioeng. 88(6), 686-689 (1999)

27. E. Martins, D. Poncelet, C.R. Ramires, D. Renard, Oil encapsulation techniques using alginate as encapsulating agent: Applications and drawbacks. J. Microencapsul. 34(8), 754-771 (2017c)

28. M. Briššová, I. Lacík, A.C. Powers, A.V. Anilkumar, T. Wang, Control and measurement of permeability for design of microcapsule cell delivery system. J. Biomed. Mater. Res. 39(1), 61-70 (1998)

29. M.P. Neubauer, M. Poehlmann, A. Fery, Microcapsule mechanics: From stability to function. Adv. Colloid Interf. Sci. 207, 65-80 (2014)

30. E.S. Chan, T.K. Lim, W.P. Voo, R. Pogaku, B.T. Tey, Z. Zhang, Effect of formulation of alginate beads on their mechanical behavior and stiffness. Particuology 9(3), 228-234 (2011)

31. Z. Marcadé-Prieto, Zhang. Mechanical characterization of microspheres - capsules, cells and microspheres: A review. J. Microencapsul. 29(3), 277-285 (2012)

32. M. Lekka, D. Sainz-Serp, A.J. Kulik, C. Wandrey, Hydrogel Microspheres: Influence of Chemical Composition on Surface Morphology, Local Elastic Properties, and Bulk Mechanical Characteristics. Langmuir 20, 9968-9977 (2004)

33. M. Carin, D. Barthès-Biesel, F. Edwards-Lévy, C. Postel, D.C. Andrei, Compression of biocompatible liquid-filled HSA-alginate capsules: Determination of the membrane mechanical properties. Biotechnol. Bioeng. 82(2), 207-212 (2003)

34. M.W. Keller, N.R. Sottos, Mechanical properties of microcapsules used in a self-healing polymer. Exp. Mech. 46(6), 725-733 (2006) 
35. S. Leick, A. Kemper, H. Rehage, Alginate/poly-L-lysine capsules: mechanical properties and drug releasecharacteristics. Soft Matter 7, 6684-6694 (2011)

36. G.B. Messaoud, L. Sánchez-González, A. Jacquot, L. Probst, S. Desobry, Alginate/sodium caseinate aqueous-core capsules: A pH-responsive matrix. J. Colloid Interface Sci. 440, 1-8 (2015)

37. S. Leick, M. Kott, P. Degen, S. Henning, T. Päsler, D. Suter, H. Rehage, Mechanical properties of liquid-filled shellac composite capsules. Phys. Chem. Chem. Phys. 13(7), 2765-2773 (2011)

38. E. Zwar, A. Kemna, L. Richter, P. Degen, H. Rehage, Production, deformation and mechanical investigation of magnetic alginate capsules. J. Phys. Condens. Matter 30(8) (2018) number 085101

39. P. Lopez-Sanchez, N. Fredriksson, A. Larsson, A. Altskärc, A. Strömb, High sugar content impacts microstructure, mechanics and release of calcium-alginate gels. Food Hydrocoll. 84, 26-33 (2018)

40. P.E. Ramos, P. Silva, M.M. Alario, L.M. Pastrana, J.A. Teixeira, M.A. Cerqueira, A.A. Vicente, Effect of alginate molecular weight and $\mathrm{M} / \mathrm{G}$ ratio in beads properties foreseeing the protection of probiotics. Food Hydrocoll. 77, 8-16 (2018)

Publisher's Note Springer Nature remains neutral with regard to jurisdictional claims in published maps and institutional affiliations. 